\title{
AGE OF ONSET AND EVOLUTION OF FABRY'S DISEASE
}

\author{
ALBERT Th. FRANCESCHETTI \\ Department of Ophthalmology, University of Geneva, Switzerland
}

Personal examination of 39 cases of Fabry's disease, with special respect to a chronogenetical analysis, revealed interesting temporal features both in the age of onset and the age of death.

Reviewing the literature on Fabry's disease, we found the description of 470 cases. Of these we personally examined 39 (Franceschetti 1973). Although the purpose of our study was not a chronogenetical analysis, we obtained some interesting temporal features.

The genetical analysis of our material produced a series of evidences on the sex-linked genetical transmission of Fabry's disease, namely: tio $1: 2$

1. The ratio, affected males/affected females, is compatible with the theoretical ra-

2. In 120 cases the gene was transmitted from mother to son.

3. Transmission from father to son was never firmly proved.

4. Sons of hemizygotes are normal.

5. Heterozygotes inherit their gene more frequently from the mother than from the father (ratio compatible with the theoretical ratio $1: 3$ ). pattern.

6. If one of the parents marries twice, children of both marriages follow the expected

7. Linkage data support a sex-linked inheritance.

8. Chromosomal examinations are normal.

\section{AGE OF ONSET}

The cornea verticillata and the angiokeratomes are the two most constant features of Fabry's disease. But patients become aware of their ophthalmological lesions only late in the disease, when hypertensive lesions also appear.

We tabulated the age at which cutaneous lesions were first noted and, despite the biases of these data, we fit a gaussian curve (Fig. 1). To do this, we disregarded patients with onset before 7. In fact, the high number of onsets reported at the age of 6 is, in our opinion, due only to the fact that the lesions were detected when the subjects went to school. We also had to exclude the cases with late onset. The mean age is 13.982 . Only 3 cases reported showed no cutaneous lesions (Jensen 1966, Kemp 1967, and Nakao et al. 1967).

A close analysis of the genealogical trees reveals the following chronogenetical facts:

1. In some families the age of onset is approximatively the same for each member; e.g.: family I of Christensen Lou et al. (1970), where case IV/10 had his first symptoms at age 10 


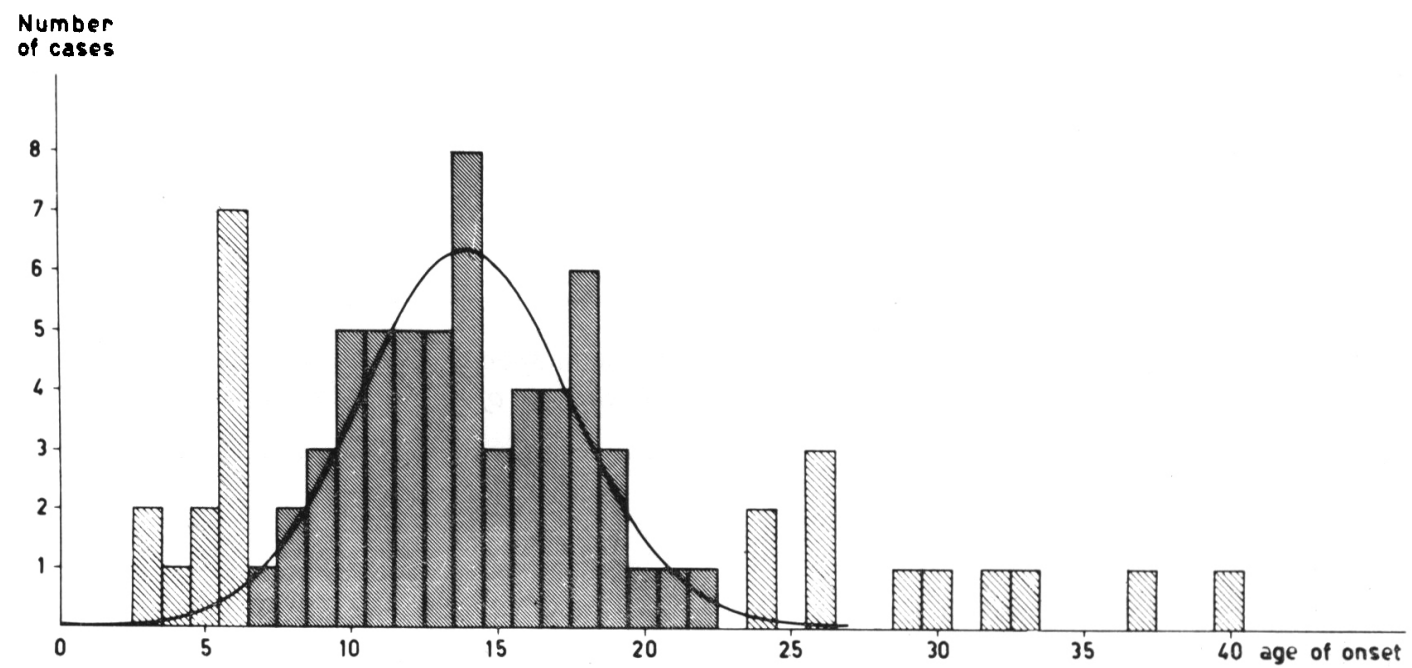

Fig. 1. Age of onset of Fabry's disease.

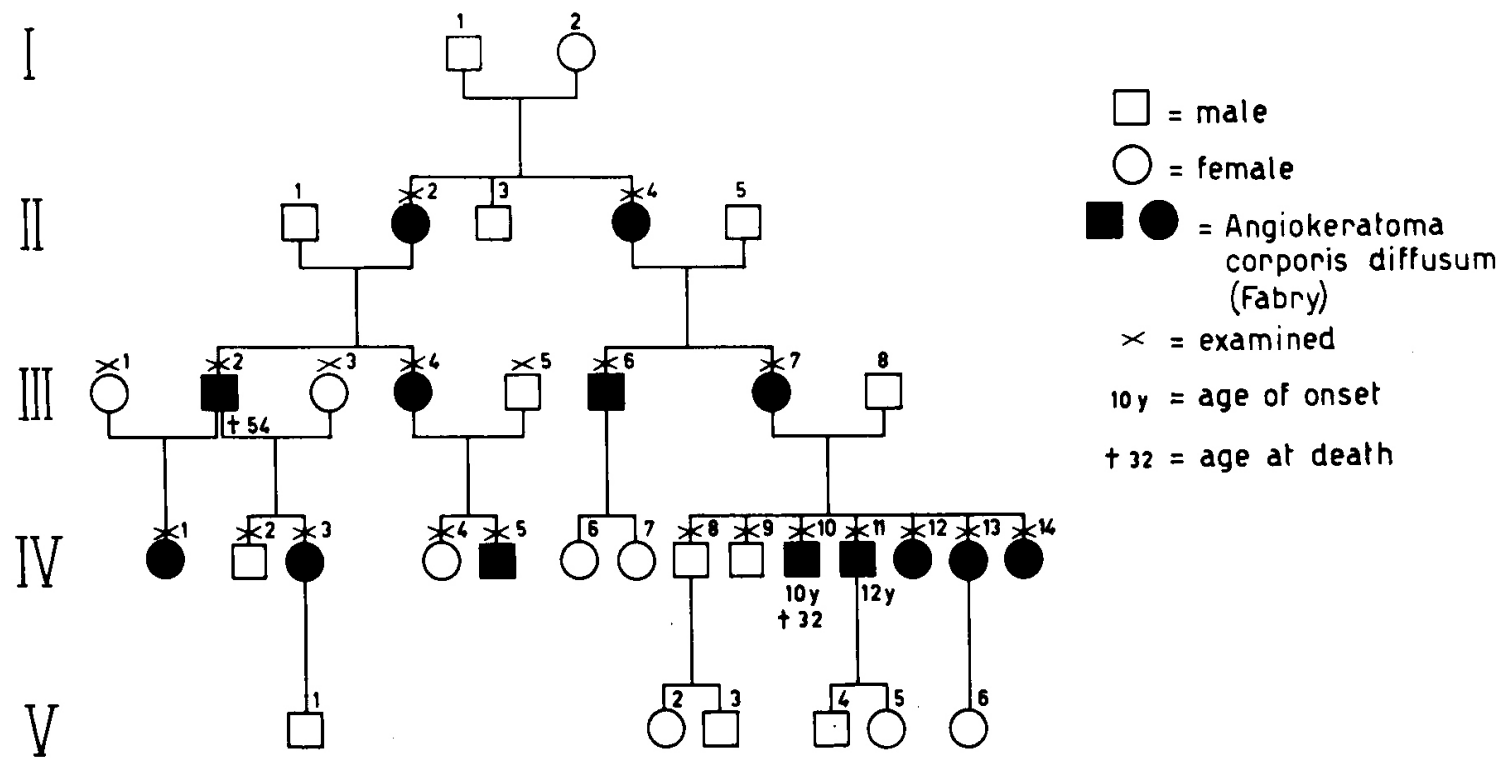

Fig. 2. Fabry's disease. [Family I of Christensen Lou et al. 1970]. 


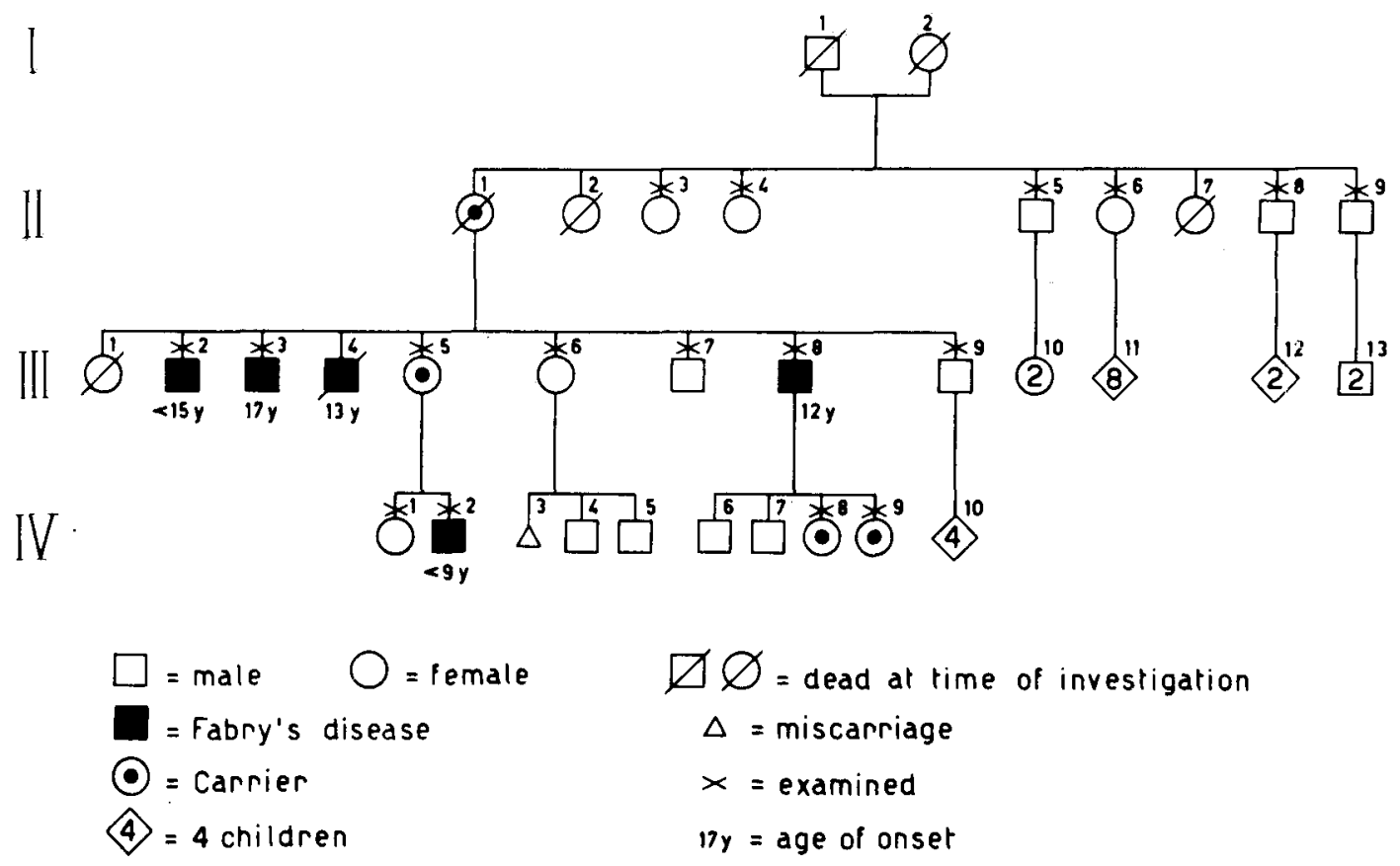

Fig. 3. Fabry's disease. [Iowa kindred of von Gemmingen et al. 1965].

and IV/11 at age 12; and for two step brothers examined by A. Denden and myself onset was at 16 (Denden and Franceschetti 1968).

2. In other families, the disease starts earlier in subsequent members; this could be explained by a progressive decay of the gametal ergon of the affected gene. In two families, we observed a gradual chronon reduction not only within a generation but also from one generation to the other (Figs. 3 and 4).

Unfortunately, there are few cases were both age of onset and age of death are reported. Therefore, nothing precise can be said on the length of the disease.

Renal transplants can halt the disease. This was observed by Philippart et al. (1972) and by Desnick et al. (1972). The suggested chronogenetical explanation is that the transplanted kidney is able to compensate the genes deficiency, when these exhaust their informational capacity.

\section{AGE OF DEATH}

Fig. 5 shows the age of death of 39 patients affected by Fabry's disease. Age ranges from 26 to 67 years.

In one family, 4 brothers died at about the same age (Fig. 6). In three families, death struck earlier in the second generation, in particular:

- 54 and 39 years of age (I/1 and III/1) for family $H$ of Wise (1960); 


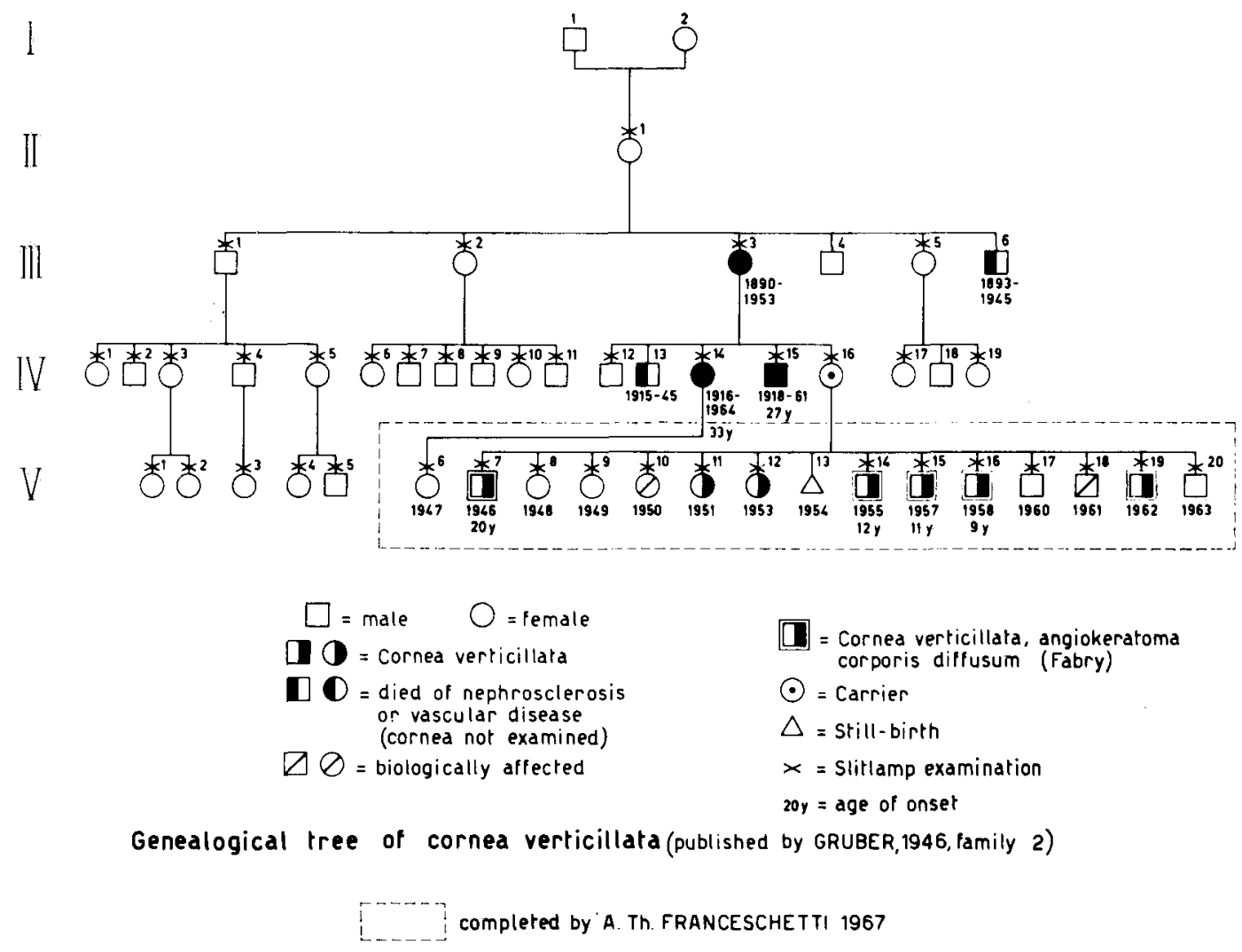

Fig. 4

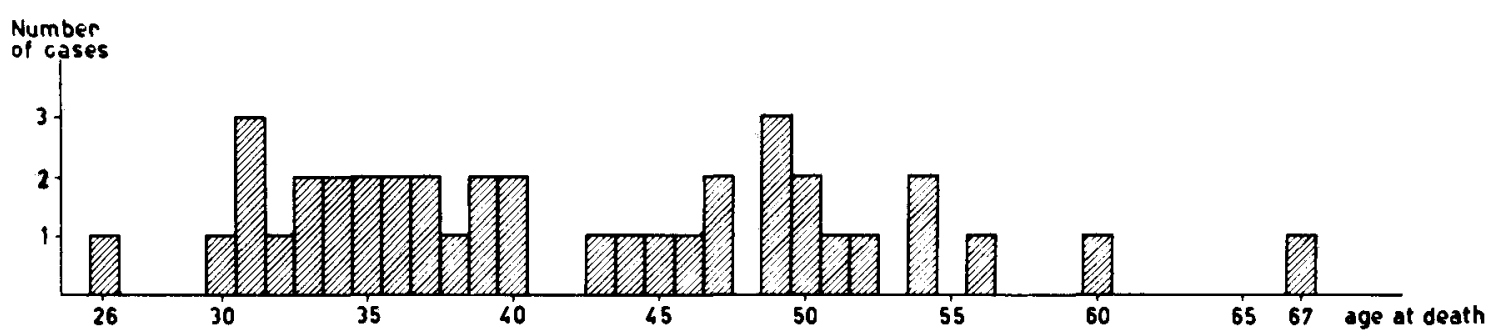

Fig. 5. Age at death of 39 cases of Fabry's disease. 


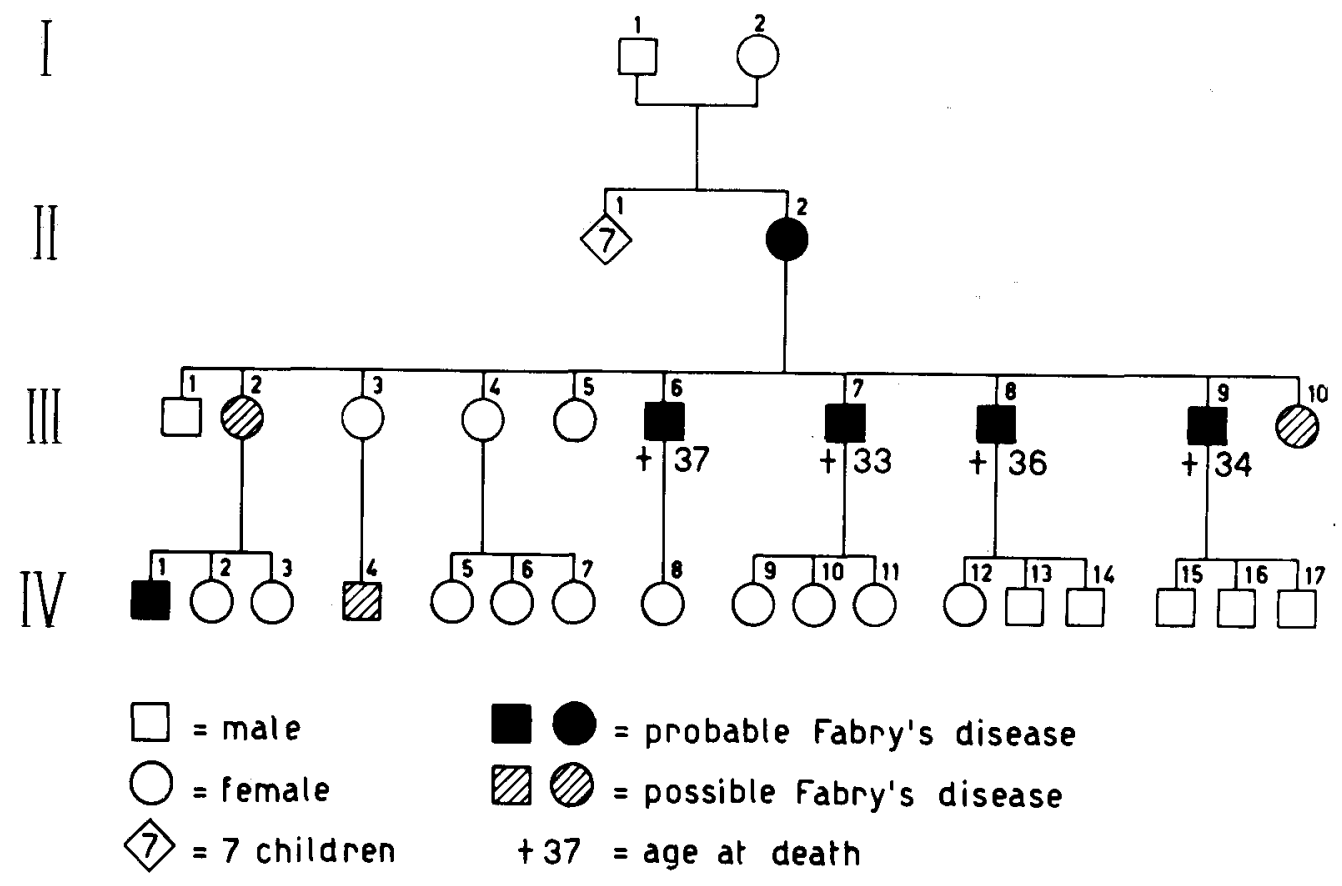

Fig. 6. Fabry's disease. [Family II of Christensen Lou 1967].

(Fig. 4);

- 52 and 43 years of age (III/6 and IV/15) for one of the families we observed in 1967

- 54 and 32 (III/2 and IV/10) for family I of Christensen Lou et al. (1970, Fig. 2).

This seems to hold true also for females, as III/3 died at 63 and IV/14 at 48 years in the family we observed (Fig. 4).

In conclusion, chronogenetical analysis revealed interesting time relations in Fabry's disease. It is to be hoped that future studies on angiokeratoma corporis diffusum will pay due attention to chronogenetical factors.

\section{BIBLIOGRAPHY}

Christensen Lou H.O. 1967. Fabry's disease. A clinical study with emphasis on neurological symptoms and signs. Second Int. Congr. Neuro-Ophthalmol., Montreal. Progress in Neuro-Ophthalmology. [pp. 363-376]. Amsterdam 1969: Excerpta Medica.

Christensen Lou H.O., Heidensleben E., Larsen H.W. 1970. The value of ocular findings in the diagnosis of angiokeratoma corporis diffusum (Fabry's disease). Acta Ophthalmol. (Kbh.), 48: 1185-1194.

Denden A., Franceschetti A.Th. 1968. Cornea Verticillata: ein Symptom des Morbus Fabry-An- derson. Ber. Dtsch. Ophthalmol. Ges., 69: 145-148.

Desnick R.J., Simmons R.L., Allen K.Y., Woods J.E., Anderson C.F., Najarian J.S., Krivit W. 1972. Correction of enzymatic deficiencies by renal transplantation. Fabry's disease. Surgery, 72: 203-211.

Franceschetti A.Th. 1967. La cornea verticillata et ses relations avec la maladie de Fabry (angiokeratoma corporis diffusum). Soc. Suisse Ophtalmol., Flims. Ophthalmologica, 156: 232-238, 1968.

Franceschetti A.Th. 1973. Etude ophtalmologique, génétique et biochimique de la maladie de Fabry. 
Revue de la littérature et analyse de 39 cas personnels. Chronica Dermatologica (Roma), 4: 371-591.

Gemmingen C. v., Kierland R.R., Opitz J.M. 1965. Angiokeratoma corporis diffusum (Fabry's disease). Arch. Dermatol., 91: 206-218.

Gruber M. 1946. "Cornea verticillata ». 2. Mitteilung. Ophthalmologica, 112: 88-91.

Jensen E. 1966. On the pathology of angiokeratoma corporis diffsum (Fabry). Acta Pathol. Microbiol. Scand., 68: 313-331.

Kemp G.L. 1967. Fabry's disease involving the myocardium and coronary arteries. Without skin manifestations. Vasc. Dis., 4: 100-106.

Nakao K., Mizuno Y., Kano S., Santo H., Yano Y., Mizoguchi H., Uono M., Shibata S., Miyatake T. 1967. A case of angiokeratoma corporis diffusum (Fabry's disease). [In Japanese]. J. Jap. Soc. Intern. Med., 56: 369-374.

Philippart M., Franklin S.S., Gorodon A. 1972. Reversal of an inborn sphingolipidosis (Fabry's disease) by kidney transplanatation. Ann. Intern. Med., 77: 195-200.

Wise D. 1960. Angiokeratoma corporis diffusum. Cambridge: Thesis.

Dr. A. Th. Franceschetti, Clinique Universitaire d'Ophtalmologie, Hôpital Cantonal, Genève, Switzerland. 